\title{
Targeting MEK5 impairs non-homologous end-joining repair and sensitizes prostate cancer to DNA damaging agents
}

\author{
Constantinos G. Broustas ${ }^{1,{ }^{*},}$ Axel J. Duval ${ }^{1}$, Kunal R. Chaudhary ${ }^{1}$, Richard A. Friedman ${ }^{2}$, \\ Renu K. Virk ${ }^{3}$, Howard B. Lieberman ${ }^{1,4}$ \\ ${ }^{1}$ Center for Radiological Research, Columbia University Vagelos College of Physicians and \\ Surgeons, Columbia University Irving Medical Center, New York, NY, USA \\ 2Biomedical Informatics Shared Resource, Herbert Irving Comprehensive Cancer Center and \\ Department of Biomedical Informatics, Columbia University Irving Medical Center, New York, NY, \\ USA \\ ${ }^{3}$ Department of Pathology and Cell Biology, Columbia University Irving Medical Center, New York, \\ NY, USA \\ ${ }^{4}$ Department of Environmental Health Sciences, Mailman School of Public Health, Columbia \\ University, New York, NY, USA
}

\section{Abstract}

Radiotherapy is commonly used to treat a variety of solid human tumors, including localized prostate cancer. However, treatment failure often ensues due to tumor intrinsic or acquired radioresistance. Here we find that the MEK5/ERK5 signaling pathway is associated with resistance to genotoxic stress in aggressive prostate cancer cells. MEK5 knockdown by RNA interference sensitizes prostate cancer cells to ionizing radiation (IR) and etoposide treatment, as assessed by clonogenic survival and short-term proliferation assays. Mechanistically, MEK5 downregulation impairs phosphorylation of the catalytic subunit of DNA-PK at serine 2056 in response to IR or etoposide treatment. Although MEK5 knockdown does not influence the initial appearance of radiation- and etoposide-induced $\gamma \mathrm{H} 2 \mathrm{AX}$ and 53BP1 foci, it markedly delays their resolution, indicating a DNA repair defect. A cell-based assay shows that non-homologous end joining (NHEJ) is compromised in cells with ablated MEK5 protein expression. Finally, MEK5 silencing combined with focal irradiation causes strong inhibition of tumor growth in mouse xenografts, compared with MEK5 depletion or radiation alone. These findings reveal a convergence between MEK5 signaling and DNA repair by NHEJ in conferring resistance to genotoxic stress in advanced prostate cancer and suggest targeting MEK5 as an effective therapeutic intervention in the management of this disease.

Users may view, print, copy, and download text and data-mine the content in such documents, for the purposes of academic research, subject always to the full Conditions of use:http://www.nature.com/authors/editorial_policies/license.html\#terms

*Correspondence should be addressed to: Dr. Constantinos G. Broustas, Center for Radiological Research, Columbia University Vagelos College of Physicians and Surgeons, 630 W. 168th St., New York, NY 10032; cgb2117@cumc.columbia.edu.

Conflict of Interest: The authors declare that they have no conflict of interest. 


\section{Introduction}

Radiotherapy is a common therapeutic modality for the treatment of human epithelial tumors, including those of prostate origin [1]. Despite considerable improvements in delivering the radiation dose with precision, therapeutic benefit in prostate cancer radiotherapy has been hampered by tumor resistance to ionizing radiation. Tumor-intrinsic pro-survival pathways, as well as upregulation of DNA repair pathways constitute major mechanisms by which malignant cells become radioresistant [2].

Cells react to genotoxic insults by engaging a highly intricate DNA damage response and repair network, which is mediated by the phosphoinositide-3-kinase-like kinases (PIKKs) DNA-PK (DNA-dependent protein kinase), ATM (ataxia telangiectasia mutated), and ATR (ATM and Rad3-related) [3]. DNA-PK and ATM are activated by DSBs, whereas ATR plays a leading role in response to DNA single-strand breaks [3]. DNA double strand breaks (DSBs) induced by ionizing radiation or certain chemotherapeutic agents potentially represent a highly toxic form of DNA damage that leads to cell death or genomic instability. In mammals, there are two major pathways for repairing DSBs. Homologous recombination (HR) is predominantly error-free repair and active during the S and G2 phases of the cell cycle, and non-homologous end-joining (NHEJ) that can be either error-free or error-prone and is active throughout the cell cycle $[4,5]$. NHEJ is the dominant pathway for repairing DNA DSBs in mammalian somatic cells [6]. Central to NHEJ repair is the DNA-PK trimeric complex, composed of DNA-PK catalytic subunit (DNA-PKcs) and DNA binding subunits, KU70 and KU80. Both KU70 and KU80 bind to DNA breaks and activate DNA-PKcs kinase activity to initiate DNA repair by NHEJ [7]. Phosphorylation at Threonine 2609 (S2609) and Serine 2056 (S2056) in response to DNA DSBs is associated with repair efficiency of DNA-PKcs [8].

Mitogen-activated protein kinase kinase 5 (MAP2K5 or MEK5) belongs to the family of MAP kinases. It is activated by the upstream kinases MEKK2 and MEKK3 at serine 311 and threonine 315 (S311/T315), or in some cases directly by c-Src [9-12]. MEK5, in turn, phosphorylates and activates extracellular signal-regulated kinase 5 (ERK5 or BMK1) at T218/Y220 [9]. The MEK5/ERK5 pathway can be activated by various stimuli such as oxidative stress, growth factors, and mitogens downstream of receptor tyrosine kinases, as well as $\mathrm{G}$ protein-coupled receptors, and culminates in the activation of a large number of transcription factors, including MEF2 (myocyte enhancer factor 2), c-JUN, NF- $\kappa \mathrm{B}$, and transcription factors that control the epithelial-mesenchymal transition (EMT) program [1318]. Furthermore, recent reports have shown that ERK5 is activated by oncogenic BRAF and promotes melanoma growth [19], whereas inhibition of ERK1/2 in melanoma leads to compensatory activation of the MEK5/ERK5 pathway [20].

The MEK5/ERK5 pathway plays a pivotal role in prostate cancer initiation and progression. MEK5 protein is overexpressed in prostate cancer cells compared with normal cells and MEK5 levels are correlated with prostate cancer metastasis [21]. Furthermore, high expression of ERK5 in prostate cancer has also been found to correlate with poor diseasespecific survival and could serve as an independent prognostic factor [22]. Moreover, ERK5 expression in prostate cancer is associated with an invasive phenotype [23]. Recently, it has 
been shown that deletion of Erk5 in an established Pten-deficient mouse model of human prostate cancer can increase T-cell infiltration and control tumor growth [24].

The present study was designed to investigate whether MEK5 downregulation sensitizes human prostate cancer cells to radiation and other agents that inflict DNA DSBs, and examine the potential mechanism of sensitization to these drugs. We show that MEK5 knockdown enhances the sensitivity of human prostate cancer cells to radiation and etoposide, which, mechanistically, can be attributed to inhibition of DNA-PKcs phosphorylation and the non-homologous end-joining process. Importantly, in vivo studies using a mouse xenograft model show that MEK5 ablation synergizes with radiation to suppress tumor growth. Our results support the hypothesis that inactivation of MEK5 in prostate cancer could be a strategy for improving the efficacy of radiotherapy in prostate cancer patients.

\section{Results}

\section{MEK5/ERK5 pathway activation in response to ionizing radiation}

It has been demonstrated previously that MEK5 and ERK5 are upregulated in human prostate cancer and are associated with metastasis and reduced patient survival [25-27]. Immunoblotting of a panel of normal and malignant human prostate cell lines showed that MEK5 is predominantly expressed in advanced prostate cancer cell lines PC3 and DU145, less in androgen-responsive LNCaP, and at very low levels in normal epithelial prostate cells (PrEC) and the immortalized, but non-tumorigenic, cell line EP156T (Supplementary Fig. 1).

The MEK5/ERK5 pathway is activated by a diverse array of growth factor, cytokines, as well as stress in the form of osmotic stress. We sought to determine whether the MEK5/ ERK5 pathway is activated in response to ionizing radiation (IR) in human prostate cancer. Using phospho-ERK5 (T218/Y220) levels as a readout for the activation of the pathway, we exposed DU145 expressing either MEK5 or control Luciferase siRNA to different doses of IR and lysed the cells 15 min post-irradiation. As shown in Fig. 1a, phospho-ERK5 levels were increased after 2 and 4 Gy of $\gamma$-rays. We repeated the experiment by exposing PC3 cells to $3 \mathrm{~Gy}$ of IR and lysing the cells at various times post-irradiation. Activation of ERK5 in response to IR was fast occurring already at the earliest examined time (5 min) and persisting up to 15-30 min, gradually diminishing at later time points (Fig. 1b). As expected no phospho-ERK5 was detected in the MEK5 depleted DU145 of PC3 cells. Similarly, PC3 cells stably expressing MEK5 shRNA had reduced levels of activated ERK5, while control cells, stably expressing a scrambled shRNA, showed increase in phospho-ERK5 (T218/ Y220) at $10 \mathrm{~min}$ post-irradiation that returned to basal levels by $4 \mathrm{~h}$ (Fig. 1c). We conclude that ionizing radiation induces a fast and transient activation of MEK5/ERK5 signaling pathway.

\section{Clonogenic survival assay}

To assess the physiological significance of IR-induced MEK5/ERK5 pathway activation, we next assessed the ability of MEK5 depletion to radiosensitize human prostate cancer cells 
using clonogenic survival assays. For this purpose, we transiently depleted MEK5 from DU145 (four non-overlapping siRNA against MEK5) or PC3 (two independent siMEK5) and two days later irradiated cells with a range of $\gamma$-rays. siRNA treatment was able to suppress MEK5 protein levels for at least 7 days (Supplementary Fig. 2a, b). The number of radioresistant clones was recorded in control cells (transfected with Luciferase siRNA) and compared with MEK5-depleted cells. MEK5 knockdown led to significant reproductive cell death after irradiation compared with irradiated cells transfected with Luciferase siRNA (Fig. 1d, e). Specifically, knocking down MEK5 by each of four non-overlapping siRNAs sensitized DU145 cells to radiation (surviving fraction at $2 \mathrm{~Gy}\left[\mathrm{SF}_{2}\right] 0.54 \pm 0.02$ ) compared to either parental cells or cells transfected with control luciferase siRNA $\left(\mathrm{SF}_{2} 0.78 \pm 0.05\right)$ (Fig. 1d). Similar radiosensitization was achieved with PC3 cells ( $\mathrm{SF}_{2} 0.35 \pm 0.04$ vs. $0.20 \pm$ 0.03 in control vs. siMEK5) (Fig. 1e).

We also performed shorter-term cell proliferation assays with PC3 and DU145 cells transiently expressing MEK5 or Luciferase siRNA irradiated or not with $4 \mathrm{~Gy}$, and cells were counted 6 days later. Transfection of untreated PC3 or DU145 cells with siMEK5 did not affect cell proliferation, appreciably. However, cells with MEK5 knockdown showed marked radiosensitization. Thus, cell proliferation of irradiated DU145 cells expressing control siRNA was reduced to $65.1 \pm 1.7 \%(\mathrm{n}=3)$, whereas in MEK5 knockdown DU145 cells proliferation was $28.2 \pm 2.9 \%(\mathrm{n}=3 ; \mathrm{p}<0.005)$, compared with unirradiated control cells. Likewise, proliferation of irradiated PC3 cells expressing Luciferase or MEK5 siRNA were $38.3 \pm 4.1 \%(\mathrm{n}=3)$ and $13.9 \pm 2.3 \%(\mathrm{n}=3)(\mathrm{p}<0.004)$, respectively (Fig. 1f). Next, we established PC3 and DU145 cells stably expressing MEK5 or scrambled (shControl) shRNA and isolated 2 clones (\#12, \#22) for PC3 and 3 clones (denoted \#5, \#7, and \#9) for DU145 cells that showed downregulation of endogenous MEK5 protein (Supplementary Fig. 2c, d). We exposed DU145/shMEK5\#9 cells and PC3/shMEK5\#12 to 4 Gy (DU145) or 3 Gy (PC3) of $\gamma$-rays. In agreement with the clonogenic assay results, silencing of $M E K 5$ resulted in significant radiosensitization in both DU145 (30.8 $\pm 2.1 \% ; \mathrm{n}=3 ; \mathrm{p}=2.9 \mathrm{E}-06)$ and PC3 (15.7 $\pm 0.4 \% ; \mathrm{n}=3 ; \mathrm{p}=6.4 \mathrm{E}-05)$ cells 6 days post-irradiation compared with shControl cells (Fig. 1g and Supplementary Fig. 3 for an additional independent experiment).

\section{Cell cycle checkpoint activation in response to IR is not affected by MEK5}

Cells exposed to genotoxic stress, such as IR, arrest the cell cycle at various phases and attempt to repair the DNA damage. In particular, cells that lack a functional p53, such as PC3 and DU145, arrest the cell cycle at G2/M phase. To determine the impact of MEK5 knockdown on cell cycle checkpoint activation after irradiation we analyzed cell cycle distribution. As expected, irradiation of either DU145 or PC3 cells caused a G2/M arrest starting at about $8 \mathrm{~h}$ post-IR, whereas by $48 \mathrm{~h}$ cells had resumed their normal cell cycle activity. However, transient or stable downregulation of MEK5 did not appreciably affect cell cycle distribution after irradiation (Supplementary Fig. 4a, b). These results suggest that MEK5 does not play a role in enforcing cell cycle checkpoint activation in response to IR. 


\section{DNA-PKcs activation in response to genotoxic stress is compromised in MEK5 knockdown cells}

Many studies have linked defects in DNA repair mechanisms to enhanced radiosensitivity. DNA double strand breaks inflicted by ionizing radiation, etoposide, and other anticancer agents lead to activation of kinases ATM and DNA-PKcs that initiate DNA repair. Activation of ATM is primarily monitored by phosphorylation of serine 1981 (S1981) and ATM is pivotal in the activation of DNA repair by homologous recombination. DNA-PKcs contains multiple Ser/Thr phosphorylation sites, and its DNA damage-inducible autophosphorylation site at S2056 is required for the repair of double-strand breaks by NHEJ [8].

Phosphorylation of serine 2056 (S2056), along with phosphorylation at threonine 2609 (T2609), are considered markers for DNA-PKcs activation in response to DNA damage [7]. Thus, to investigate the potential molecular mechanisms underlying the enhanced sensitivity of MEK5 knockdown in prostate cancer cells to IR, we examined phosphorylation status of DNA-PKcs and ATM in response to DNA damage. PC3 cells transiently expressing a control Luciferase siRNA (siLUC) responded to $3 \mathrm{~Gy} \gamma$-rays by a robust increase in phosphorylation of DNA-PKcs at S2056 and T2609 that was detectable at the earliest time point examined (15 min) post-irradiation. DNA-PKcs phosphorylation signal was diminished to near basal levels $3 \mathrm{~h}$ post-irradiation, suggesting completion of DNA repair [7]. In contrast, DNA-PKcs phosphorylation was severely diminished in MEK5 depleted PC3 cells (Fig. 2a). On the other hand, ATM phosphorylation at S1981 in response to IR was comparable between control and MEK5-depleted PC3 cells (Fig. 2a). These results were also confirmed by using DU145 cells (Fig. 2b). We also examined phosphorylation of DNAPKcs at S2056 using PC3 cells stably expressing MEK5 shRNA (clones \#12, \#22) or control shRNA (shControl) (Fig. 2c and Supplementary Fig. 5), as well as DU145 cells expressing MEK5 shRNA (clone \#7) (Fig. 2d) with similar results. Finally, ectopic expression of a MEK5 construct (Supplementary Fig. 1e) in PC3/shMEK5 (clone \#12) cells showed that DNA-PKcs S2056 phosphorylation was restored to normal levels in response to irradiation, while phospho-ATM remained at similar levels between shMEK5 and shMEK5/MEK5 cells (Fig. 2e).

We also examined the impact of MEK5 silencing on the response to IR of two additional cell lines, the non-tumorigenic prostate epithelial cells EP156T and the androgen-responsive LNCaP cells. In contrast to PC3 and DU145, MEK5 ablation did not have an impact on the phosphorylation of DNA-PKcs (S2056) and ATM (S1981) in response to IR (Supplementary Fig. 6a, b). Likewise, cell proliferation assay showed that MEK5 ablation did not sensitize LNCaP cells to IR (Supplementary Fig. 6c).

To validate the impact of MEK5 silencing on DNA-PKcs activation further, we exposed PC3 and DU145 cells to etoposide and phleomycin, two compounds that inflict cell damage by generating DNA double strand breaks, which are predominantly repaired by NHEJ [28]. We first performed a dose response study using various concentrations $(0,0.5,1,2.5,5$, and 10 $\mu \mathrm{M}$ ) of etoposide with PC3/shControl and PC3/shMEK5-12 cells. As shown in Fig. 3a, PC3 cells with MEK5 knockdown were exquisitely sensitive to etoposide treatment compared with control PC3 cells. In a similar experiment, we treated PC3/shControl and PC3/ shMEK5-12 cells with $10 \mu \mathrm{M}$ etoposide for $16 \mathrm{~h}$, removed the drug, and incubated cells for 
an additional 4 days after which we counted the cells. While total cell count of untreated PC3 expressing shMEK5 did not differ from control cells, etoposide-exposed PC3/shMEK5 showed an $80 \%$ reduction in cell numbers compared with etoposide-treated control cells (Fig. 3b). Furthermore, treating PC3 cells with $10 \mu \mathrm{M}$ of etoposide resulted in a robust increase of DNA-PKcs phosphorylation at S2056 (Fig. 3c). In contrast, phospho-DNA-PKcs was significantly lower in PC3/shMEK5 cells for the whole time course (Fig $3 \mathrm{c}$ and Supplementary Fig. 7a). These results were further confirmed with DU145 cells, as well (Supplementary Fig. 7b). ATM activation was not different between control and MEK5 knockdown PC3 cells. Finally, we treated PC3 and DU145 cells with $60 \mu \mathrm{g} / \mathrm{mL}$ of phleomycin for $2 \mathrm{~h}$ to generate DSBs, removed the drug, and incubated the cells in drug-free culture medium for up to $4 \mathrm{~h}$. As seen with IR and etoposide, the expected increase in phospho-S2056 was observed only in the cells with normal levels of MEK5, but not in cells with MEK5 knockdown (Fig. 3d). Unlike DNA-PKcs, ATM activation in response to phleomycin was independent of MEK5 in both cell lines. Collectively, these results show that MEK5 is required for full activation of DNA-PKcs in response to DSB genotoxic stress, and thus MEK5 acts upstream of DNA-PKcs. However, ATM activation is independent of MEK5.

\section{MEK5 ablation delays IR-induced foci resolution}

An early response to DSBs is phosphorylation of $\mathrm{H} 2 \mathrm{AX}$, a variant of histone $\mathrm{H} 2 \mathrm{~A}$, at serine 139, which is carried out by both ATM and DNA-PKcs [3]. Phosphorylated H2AX, called $\gamma \mathrm{H} 2 \mathrm{AX}$, spreads from the double strand break over several megabases, and this can be visualized as foci by immunofluorescence using phospho-Ser139 antibodies. Similar to $\mathrm{H} 2 \mathrm{AX}, 53 \mathrm{BP} 1$ is recruited to break sites and co-localizes with $\gamma \mathrm{HA} 2 \mathrm{X}$. 53BP1 has been shown to be important for DNA repair by NHEJ [29]. To gain further insight into how MEK5 depletion sensitizes cells to genotoxic stress, we monitored the kinetics of $\gamma \mathrm{H} 2 \mathrm{AX}$ and 53BP1 foci formation in PC3 cells after exposure to $3 \mathrm{~Gy} \gamma$-rays. The number of foci in unirradiated cells was low and it did not change with MEK5 silencing. As expected, radiation induced a rapid $\gamma \mathrm{H} 2 \mathrm{AX}$ and 53BP1 foci formation reaching maximum number within $30 \mathrm{~min}$ (Fig. 4a, c, d). MEK5 depletion (Fig. 4b) did not change the initial appearance of foci numbers. Subsequently, foci numbers in control PC 3 cells were markedly diminished $2 \mathrm{~h}$ post-irradiation and returned to basal levels by $24 \mathrm{~h}$. However, MEK5-depleted cells significantly delayed resolution of foci and they persisted above basal levels even after $48 \mathrm{~h}$ (Fig. 4a, c, d). We repeated the immunofluorescence experiments using transient Luciferase and $M E K 5$ siRNA transfection of PC3 cells with comparable results (Supplementary Fig. 8). Finally, we exposed PC3 cells to $10 \mu \mathrm{M}$ etoposide and monitored $\mathrm{H} 2 \mathrm{AX}$ and 53BP1 foci formation and resolution. In agreement with the IR treatment, exposure to etoposide resulted in increased number of foci at $30 \mathrm{~min}$ and $2 \mathrm{~h}$, comparable for both control and MEK5 knockdown PC3 cells (Fig. 5a, b, c). However, foci resolution occurred much faster in control cells than in MEK5 silenced cells. We conclude that although the initial response to DNA damage is not dependent on MEK5 presence, the resolution and thus DNA repair of the damage is markedly delayed by MEK5 knockdown. 


\section{MEK5 knockdown impairs non-homologous end joining}

Next, we performed experiments to test directly the ability of MEK5 to promote NHEJ by using a cell-based assay [30, 31]. pEGFP-N1 plasmid (Clontech) was digested with HindIII restriction endonuclease and transfected into PC3 cells expressing normal or reduced levels of MEK5. As a control, we treated PC 3 cells with $2 \mu \mathrm{M}$ NU7441, a DNA-PKcs-specific inhibitor. Transient transfection efficiency with the initial uncut plasmid was approximately $30 \%$ for PC3, PC3/shMEK5, and PC3/NU7441 cells as judged by the number of EGFP fluorescent cells measured under the microscope (Fig. 6a). Transiently transfected digested plasmid into PC 3 cells resulted in approximately $10 \%$ of green fluorescent cells that express the protein. In contrast, PC3/shMEK5 produced almost 7 times fewer EGFP-expressing cells (1.5\%), whereas the proportion of EGFP-positive cells after treatment with NU7441 was approximately 1\% (Fig. 6b). Thus, MEK5 downregulation impairs NHEJ.

\section{Combination of MEK5 blockade and ionizing radiation impairs tumor growth in vivo}

To evaluate the efficacy of MEK5 knockdown combined with radiation to inhibit the growth of prostate cancer cells in mouse xenografts, we injected mice subcutaneously with PC3 cells expressing either shControl or ShMEK5\#12. We chose $S h M E K 5$ clone 12, as this clone showed the greater efficiency in downregulating endogenous MEK5 and, in vitro proliferation assays showed no appreciable difference in cell proliferation between shControl and shMEK5 PC3 cells (Supplementary Fig. 9). Mice bearing subcutaneous shControl or shMEK5 xenografts were either left untreated or exposed to a single dose of 4 Gy, delivered specifically to the tumor by the Small Animal Radiation Research Platform (SARRP) irradiator using the onboard imager of the SARRP for image guided localization of the tumor (Supplementary Fig. 10) [32]. In agreement with in vitro proliferation assay, unirradiated shMEK5 cell growth showed a small but not significant $(\mathrm{p}=0.5)$ impairment of growth when compared with unirradiated shControl cell growth. Likewise, exposure of shControl tumors to $4 \mathrm{~Gy} \gamma$-rays had no effect on tumor growth compared with unirradiated shControl tumors ( $\mathrm{p}=0.5$; Fig. 7). In contrast, shMEK5 cells exposed to radiation grew fivefold more slowly compared with unirradiated shMEK5 cells (p < 1E-04) (Fig. 7). In summary, these findings demonstrate that whereas MEK5 depletion or IR used separately have only a moderate impact on PC3 cells grown in mouse xenografts, the combination of MEK5 blockade with IR leads to a dramatic inhibition of tumor growth.

\section{Discussion}

In this study, we identified a critical role of MEK5 in mediating resistance to DNA damaging agents, such as ionizing radiation and etoposide, in prostate cancer cells. Our in vitro and in vivo investigations demonstrate that MEK5 silencing sensitized PC3 and DU145 aggressive prostate cancer cell lines to IR, etoposide, and phleomycin through inactivation of DNA-PKcs and NHEJ repair. In contrast, neither EP156T nor LNCaP cell lines were affected by MEK5 knockdown, most likely because these cells express relatively lower protein levels compared with PC3 and DU145. Furthermore, in the androgen receptor (AR)positive LNCaP cells, AR drives DNA-PKcs expression and activation in response to genotoxic stress $[33,34]$. As a result, LNCaP cells possess much higher levels of DNA-PKcs and active NHEJ. Thus, enhanced activity of DNA-PKcs combined with lower levels of 
MEK5 protein in LNCaP cells could preclude MEK5 from regulating DNA-PKcs phosphorylation levels.

While ATM is activated by IR, etoposide, or phleomycin equally well between control and MEK5 knockdown cells, MEK5 silencing impairs phosphorylation of DNA-PKcs at S2056 and T2609 in response to genotoxic stress, indicating reduced activation. We find that the combination of MEK5 abrogation with etoposide has a greater impact on prostate cancer cell survival than radiation. Etoposide treatment generates DSBs that are mainly repaired by NHEJ [35]. In contrast, IR creates DSBs that are repaired by both NHEJ and HR [35]. Thus, MEK5 ablation that diminishes DNA-PKcs phosphorylation and impairs NHEJ is expected to significantly reduce cell survival, when combined with etoposide.

It has been shown that IR-induced DNA-PKcs autophosphorylation at S2056 is regulated in a cell cycle-dependent manner with attenuated phosphorylation in the $S$ phase [8]. However, we confirmed that MEK5 silencing had no impact on cell cycle distribution and neither altered cell cycle arrest after IR. It is well established that elevated DNA-PKcs activity in various human cancers results in increased resistance to DNA damage. DNA-PKcs is associated with poor disease outcome [36] and predicts response to radiotherapy in advanced prostate cancer [37, 38], whereas knockdown of DNA-PKcs sensitizes DU145 and PC3 cells to ionizing radiation [39]. However, DNA-PKcs is a ubiquitously expressed protein and its inhibition is expected to sensitize both normal epithelial and malignant prostate cells to radiation. In contrast, MEK5 is predominantly expressed in prostate cancer cells and thus targeting MEK5 would radiosensitize mainly tumor cells.

DSB generated by IR result in the formation of $\gamma \mathrm{H} 2 \mathrm{AX}$ and 53BP1 foci, and persistence of $\gamma \mathrm{H} 2 \mathrm{AX}$ foci indicate delayed repair and correlates with radiosensitivity [40-42]. The initial generation of IR-induced $\gamma \mathrm{H} 2 \mathrm{AX}$ and 53BP1 foci formation was similar between MEK5 knockdown and control cells. This can be attributed to ATM activation, which is known to play a dominant role in the generation of $\gamma \mathrm{H} 2 \mathrm{AX}$, at least at early times post-irradiation [43]. In contrast, the resolution and thus repair of damage foci was markedly delayed in MEK5 knockdown cells compared with control cells. This is consistent with impaired DNAPKcs action [43]. Furthermore, cell-based assays confirmed that NHEJ activity was significantly compromised in MEK5 knockdown cells.

In the current study, we provide evidence for the first time that a member of the MAP kinase family, MEK5, has an impact on DNA-PKcs phosphorylation and NHEJ repair in response to genotoxic stress. Members of the mitogen-activated protein kinases (MAPK) family, especially the MEK1/2/ERK1/2 pathway, have been functionally associated with tumor DNA damage response and repair pathway, albeit with variable outcomes. Thus, activation of ATM by radiation downregulates phospho-ERK1/2, and this downregulation is associated with radioresistance in human squamous cell carcinoma cell lines [44]. Similarly, ERK1/2 activation in response to etoposide, which is abrogated in ATM knockout cells, leads to increased apoptosis and sensitization to the drug [45]. In contrast, ATM inhibition partly blocks phospho-ERK1/2 and diminishes HR in response to radiation, whereas inhibition of ERK1/2 activity reduced phosphorylation of ATM at S1981 in glioma cells [46].

Furthermore, treatment of pancreatic cancer cells with the MEK1/2-specific inhibitor 
trametinib resulted in significant radiosensitization by suppressing both HR and NHEJ [47]. In this case, it was noted that total DNA-PKcs levels were reduced in the trametinib-treated cells. However, inhibition of ERK1/2 has also been shown to increase DNA-PKcs activation and promote DSB repair by NHEJ in response to etoposide in breast cancer cells [48]. In our study, ERK1/2 activation in response to IR was not detected in PC3 cells (unpublished results). However, EGF treatment of PC3 cells was able to induce phospho-ERK1/2, implying that the MEK1/2/ERK1/2 pathway is intact in these cells. On the other hand, DU145 cells express active ERK1/2 constitutively and phospho-ERK1/2 levels were not further induced by IR. Recently a study was published that showed ERK5 confers radioresistance to lung adenocarcinoma cell lines [49]. However, the mode of action of ERK5 in response to IR differs significantly from the present study. Thus, whereas ERK5 knockdown combined with radiation leads to compromised G2/M cell cycle arrest, our results show that MEK5 downregulation does not affect the cell cycle checkpoint response. Moreover, it was shown that IR caused sustained activation of ERK5, whereas we find that activation of ERK5 in prostate cancer cells is fast and transient, reaching maximal levels of phosphorylation at around 10-30 min, diminishing thereafter and becoming undetectable by $2 \mathrm{hr}$ post-irradiation. These differences may be attributed to different cancer types or, alternatively, to the fact that ERK5 has additional, MEK5-independent functions, and thus the impact of MEK5 knockdown may differ from that of ERK5 depletion [50].

In conclusion, our results support the mechanism that MEK5 inhibition sensitizes prostate cancer cells to genotoxic stress by severely impairing DNA-PKcs autophosphorylation and DNA repair by NHEJ. Our in vivo experiments show that downregulation of MEK5 combined with irradiation markedly sensitizes prostate cancer cells to radiotherapy and support targeting MEK5 as a potential clinical intervention for intermediate and high-risk prostate cancer patients treated with radiotherapy.

\section{Materials and methods}

Detailed experimental procedures describing cell culture, cell proliferation assays, irradiation, clonogenic survival assay, RNA interference and plasmid construction, cell cycle analysis, Western blot analysis, immunofluorescence, NHEJ assay, animal studies, and statistical analysis are included in the Supplementary Materials and Methods document. A list of the antibodies used and their dilution is provided in Supplementary Table 1.

\section{Supplementary Material}

Refer to Web version on PubMed Central for supplementary material.

\section{Acknowledgements}

This work is supported by the Department of Defense Prostate Cancer Research Program, W81XWH-15-1-0296 (CGB). This study also used the resources of the Herbert Irving Comprehensive Cancer Center Flow Cytometry, Radiation Research, and Confocal and Specialized Microscopy Shared Resources funded in part through Center Grant P30CA013696. We thank Theresa Swayne and Laura Munteanu from the Confocal and Specialized Microscopy Shared Resource of the Irving Cancer Research Center (ICRC) and Drs. Siu-Hong Ho, Wei Wang, and Caisheng Lu from the Flow Cytometry Shared Resource of the Herbert Irving Comprehensive Cancer Center at Columbia University Irving Medical Center for their help in performing the immunofluorescence and flow cytometry experiments. 


\section{References}

1. Bolla M, Van Tienhoven G, Warde P, Dubois JB, Mirimanoff RO, Storme G, et al. External irradiation with or without long-term androgen suppression for prostate cancer with high metastatic risk: 10-year results of an EORTC randomised study. Lancet Oncol. 2010;11(11):1066-1073. [PubMed: 20933466]

2. Palacios DA, Miyake M, Rosser CJ. Radiosensitization in prostate cancer: mechanisms and targets. BMC Urol. 2013;13:4. [PubMed: 23351141]

3. Ciccia A, Elledge SJ. The DNA damage response: making it safe to play with knives. Mol Cell. 2010;40(2):179-204. [PubMed: 20965415]

4. San Filippo J, Sung P, Klein H. Mechanism of eukaryotic homologous recombination. Annu Rev Biochem. 2008;77:229-257. [PubMed: 18275380]

5. Lieber MR. The mechanism of human nonhomologous DNA end joining. J Biol Chem. 2008;283(1):1-5. [PubMed: 17999957]

6. Jeggo PA.DNA breakage and repair. Adv Genet. 1998;38:185-218. [PubMed: 9677708]

7. Davis AJ, Chen BP, Chen DJ. DNA-PK: a dynamic enzyme in a versatile DSB repair pathway. DNA Repair (Amst). 2014;17:21-29. [PubMed: 24680878]

8. Chen BP, Chan DW, Kobayashi J, Burma S, Asaithamby A, Morotomi-Yano K, et al. Cell cycle dependence of DNA-dependent protein kinase phosphorylation in response to DNA double strand breaks. J Biol Chem. 2005;280(15):14709-14715. [PubMed: 15677476]

9. Zhou G, Bao ZQ, Dixon JE. Components of a new human protein kinase signal transduction pathway. J Biol Chem. 1995:270(21):12665-12669. [PubMed: 7759517]

10. Sun W, Kesavan K, Schaefer BC, Garrington TP, Ware M, Johnson NL, et al. MEKK2 associates with the adapter protein Lad/RIBP and regulates the MEK5-BMK1/ERK5 pathway. J Biol Chem. 2001:276(7):5093-5100. [PubMed: 11073940]

11. Chao TH, Hayashi M, Tapping RI, Kato Y, Lee JD. MEKK3 directly regulates MEK5 activity as part of the big mitogen-activated protein kinase 1 (BMK1) signaling pathway. J Biol Chem. 1999:274(51):36035-36038. [PubMed: 10593883]

12. Suzaki Y, Yoshizumi M, Kagami S, Koyama AH, Taketani Y, Houchi H, et al. Hydrogen peroxide stimulates c-Src-mediated big mitogen-activated protein kinase 1 (BMK1) and the MEF2C signaling pathway in PC12 cells: potential role in cell survival following oxidative insults. J Biol Chem. 2002:277(11):9614-9621. [PubMed: 11782488]

13. Arnoux V, Nassour M, L'Helgoualc'h A, Hipskind RA, Savagner P. Erk5 controls Slug expression and keratinocyte activation during wound healing. Mol Biol Cell. 2008:19(11):4738-47349. [PubMed: 18716062]

14. Zhou C, Nitschke AM, Xiong W, Zhang Q, Tang Y, Bloch M, et al. Proteomic analysis of tumor necrosis factor-alpha resistant human breast cancer cells reveals a MEK5/Erk5-mediated epithelial-mesenchymal transition phenotype. Breast Cancer Res. 2008:10(6):R105. [PubMed: 19087274]

15. Schweppe RE, Cheung TH, Ahn NG. Global gene expression analysis of ERK5 and ERK1/2 signaling reveals a role for HIF-1 in ERK5-mediated responses. J Biol Chem. 2006:281(30):20993-21003. [PubMed: 16735500]

16. English JM, Vanderbilt CA, Xu S, Marcus S, Cobb MH. Isolation of MEK5 and differential expression of alternatively spliced forms. J Biol Chem. 1995;270(48):28897-288902. [PubMed: 7499418]

17. Seyfried J, Wang X, Kharebava G, Tournier C. A novel mitogen-activated protein kinase docking site in the $\mathrm{N}$ terminus of MEK5alpha organizes the components of the extracellular signalregulated kinase 5 signaling pathway. Mol Cell Biol. 2005;25(22):9820-9828. [PubMed: 16260599]

18. Cameron SJ, Abe J, Malik S, Che W, Yang J. Differential role of MEK5alpha and MEK5beta in BMK1/ERK5 activation. J Biol Chem. 2004;279(2):1506-1512. [PubMed: 14583600]

19. Tusa I, Gagliardi S, Tubita A, Pandolfi S, Urso C, Borgognoni L, et al. ERK5 is activated by oncogenic BRAF and promotes melanoma growth. Oncogene. 2018;37(19):2601-2614. [PubMed: 29483645] 
20. Benito-Jardón L, Díaz-Martínez M, Arellano-Sánchez N, Vaquero-Morales P, Esparís-Ogando A, Teixidó J. Resistance to MAPK Inhibitors in Melanoma Involves Activation of the IGF1R-MEK5Erk5 Pathway. Cancer Res. 2019;79(9):2244-2256. [PubMed: 30833419]

21. Ghosh AK, Steele R, Ray RB. c-myc Promoter-binding protein 1 (MBP-1) regulates prostate cancer cell growth by inhibiting MAPK pathway. J Biol Chem. 2005;280(14):14325-14330. [PubMed: 15805119]

22. Regan CP, Li W, Boucher DM, Spatz S, Su MS, Kuida K. Erk5 null mice display multiple extraembryonic vascular and embryonic cardiovascular defects. Proc Natl Acad Sci U S A. 2002;99(14):9248-9253. [PubMed: 12093914]

23. Yan L, Carr J, Ashby PR, Murry-Tait V, Thompson C, Arthur JS. Knockout of ERK5 causes multiple defects in placental and embryonic development. BMC Dev Biol. 2003;3:11. [PubMed: 14675480]

24. Loveridge CJ, Mui EJ, Patel R, Tan EH, Ahmad I, Welsh M, et al. Increased T-cell Infiltration Elicited by Erk5 Deletion in a Pten-Deficient Mouse Model of Prostate Carcinogenesis. Cancer Res. 2017;77(12):3158-3168. [PubMed: 28515147]

25. Mehta PB, Jenkins BL, McCarthy L, Thilak L, Robson CN, Neal DE, et al. MEK5 overexpression is associated with metastatic prostate cancer, and stimulates proliferation, MMP-9 expression and invasion. Oncogene. 2003;22(9):1381-1389. [PubMed: 12618764]

26. McCracken SR, Ramsay A, Heer R, Mathers ME, Jenkins BL, Edwards J, et al. Aberrant expression of extracellular signal-regulated kinase 5 in human prostate cancer. Oncogene. 2008;27(21):2978-2988. [PubMed: 18071319]

27. Ramsay AK, McCracken SR, Soofi M, Fleming J, Yu AX, Ahmad I, et al. ERK5 signalling in prostate cancer promotes an invasive phenotype. Br J Cancer. 2011;104(4):664-672. [PubMed: 21266977]

28. Adachi N, Suzuki H, Liizumi S, Koyama H. Hypersensitivity of nonhomologous DNA end-joining mutants to VP-16 and ICRF-193: implications for the repair of topoisomerase II-mediated DNA damage. J Biol Chem. 2003;278:35897-35902. [PubMed: 12842886]

29. Panier S, Durocher D. Push back to respond better: regulatory inhibition of the DNA double-strand break response. Nat Rev Mol Cell Biol. 2013;14(10):661-672. [PubMed: 24002223]

30. Wang HC, Chou WC, Shieh SY, Shen CY. Ataxia telangiectasia mutated and checkpoint kinase 2 regulate BRCA1 to promote the fidelity of DNA end-joining. Cancer Res. 2006;66(3):1391-400. [PubMed: 16452194]

31. Kim MR, Lee J, An YS, Jin YB, Park IC, Chung E, et al. TGF $\beta 1$ protects cells from $\gamma$-IR by enhancing the activity of the NHEJ repair pathway. Mol Cancer Res. 2015;13(2):319-329. [PubMed: 25319009]

32. Wu CC, Chaudhary KR, Na YH, Welch D, Black PJ, Sonabend AM, et al. Quality Assessment of Stereotactic Radiosurgery of a Melanoma Brain Metastases Model Using a Mouselike Phantom and the Small Animal Radiation Research Platform. Int J Radiat Oncol Biol Phys. 2017;99(1):191-201. [PubMed: 28816146]

33. Polkinghorn WR, Parker JS, Lee MX, Kass EM, Spratt DE, Iaquinta PJ, et al. Androgen receptor signaling regulates DNA repair in prostate cancers. Cancer Discov. 2013;3(11):1245-53. [PubMed: 24027196]

34. Goodwin JF, Schiewer MJ, Dean JL, Schrecengost RS, de Leeuw R, Han S, et al. A hormone-DNA repair circuit governs the response to genotoxic insult. Cancer Discov. 2013;3(11):1254-71. [PubMed: 24027197]

35. Shibata A, Conrad S, Birraux J, Geuting V, Barton O, Ismail A, et al. Factors determining DNA double-strand break repair pathway choice in G2 phase. EMBO J. 2011;30(6):1079-92. [PubMed: 21317870]

36. Brenner JC, Ateeq B, Li Y, Yocum AK, Cao Q, Asangani IA, et al. Mechanistic rationale for inhibition of poly(ADP-ribose) polymerase in ETS gene fusion-positive prostate cancer. Cancer Cell. 2011;19(5):664-678. [PubMed: 21575865]

37. Ni X, Zhang Y, Ribas J, Chowdhury WH, Castanares M, Zhang Z, et al. Prostate-targeted radiosensitization via aptamer-shRNA chimeras in human tumor xenografts. J Clin Invest. 2011;121(6):2383-2390. [PubMed: 21555850] 
38. Bouchaert P, Guerif S, Debiais C, Irani J, Fromont G. DNA-PKcs expression predicts response to radiotherapy in prostate cancer. Int J Radiat Oncol Biol Phys. 84(5):1179-1185.

39. Collis SJ, Swartz MJ, Nelson WG, DeWeese TL. Enhanced radiation and chemotherapy-mediated cell killing of human cancer cells by small inhibitory RNA silencing of DNA repair factors. Cancer Res. 2003;63(7):1550-1554. [PubMed: 12670903]

40. Banáth JP, Macphail SH, Olive PL. Radiation sensitivity, H2AX phosphorylation, and kinetics of repair of DNA strand breaks in irradiated cervical cancer cell lines. Cancer Res. 2004;64(19):7144-7149. [PubMed: 15466212]

41. Olive PL, Banáth JP. Phosphorylation of histone H2AX as a measure of radiosensitivity. Int J Radiat Oncol Biol Phys. 2004;58(2):331-335. [PubMed: 14751500]

42. Taneja N, Davis M, Choy JS, Beckett MA, Singh R, Kron SJ, et al. Histone H2AX phosphorylation as a predictor of radiosensitivity and target for radiotherapy. J Biol Chem. 2004;279(3):22732280. [PubMed: 14561744]

43. Stiff T, O’Driscoll M, Rief N, Iwabuchi K, Löbrich M, Jeggo PA. ATM and DNA-PK function redundantly to phosphorylate $\mathrm{H} 2 \mathrm{AX}$ after exposure to ionizing radiation. Cancer Res. 2004 1;64(7):2390-2396. [PubMed: 15059890]

44. Nyati MK, Feng FY, Maheshwari D, Varambally S, Zielske SP, Ahsan A, et al. Ataxia telangiectasia mutated down-regulates phospho-extracellular signal-regulated kinase $1 / 2$ via activation of MKP-1 in response to radiation. Cancer Res. 2006;66(24):11554-9. [PubMed: 17178844]

45. Tang D, Wu D, Hirao A, Lahti JM, Liu L, Mazza B, et al. ERK activation mediates cell cycle arrest and apoptosis after DNA damage independently of p53. J Biol Chem. 2002;277(15):12710-12717. [PubMed: 11821415]

46. Golding SE, Rosenberg E, Neill S, Dent P, Povirk LF, Valerie K. Extracellular signal-related kinase positively regulates ataxia telangiectasia mutated, homologous recombination repair, and the DNA damage response. Cancer Res. 2007;67(3):1046-1053. [PubMed: 17283137]

47. Estrada-Bernal A, Chatterjee M, Haque SJ, Yang L, Morgan MA, Kotian S, et al. MEK inhibitor GSK1120212-mediated radiosensitization of pancreatic cancer cells involves inhibition of DNA double-strand break repair pathways. Cell Cycle. 2015;14(23):3713-3724. [PubMed: 26505547]

48. Wei F, Yan J, Tang D, Lin X, He L, Xie Y, et al. Inhibition of ERK activation enhances the repair of double-stranded breaks via non-homologous end joining by increasing DNA-PKcs activation. Biochim Biophys Acta. 2013;1833(1):90-100. [PubMed: 23098854]

49. Jiang W, Jin G, Cai F, Chen X, Cao N, Zhang X, et al. Extracellular signal-regulated kinase 5 increases radioresistance of lung cancer cells by enhancing the DNA damage response. Exp Mol Med. 2019;51(2):19.

50. Pavan S, Meyer-Schaller N, Diepenbruck M, Kalathur RKR, Saxena M, Christofori G. A kinomewide high-content siRNA screen identifies MEK5-ERK5 signaling as critical for breast cancer cell EMT and metastasis. Oncogene. 2018;37(31):4197-4213. [PubMed: 29713055] 

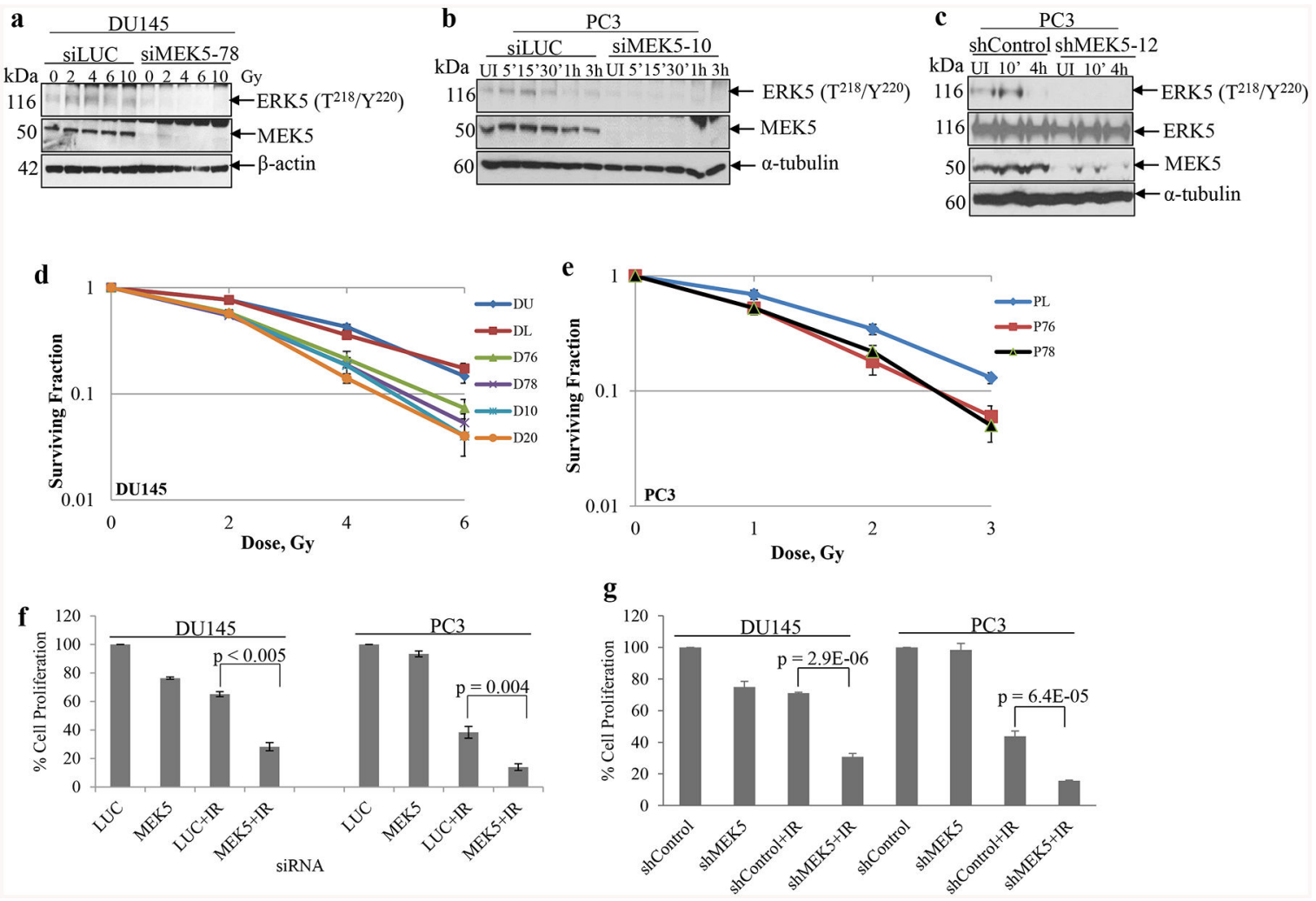

Fig. 1.

MEK5 silencing sensitizes cells to radiation. a DU145 cells were transiently transfected with Luciferase (siLUC) or MEK5 (siMEK5-78) siRNA. Two days later, cells were serumstarved for $24 \mathrm{~h}$ and irradiated by various doses of $\gamma$-radiation. Fifteen minutes later, cells were lysed and proteins were subjected to immunoblotting with the indicated antibodies. $\mathbf{b}$ Time course activation of ERK5 in response to ionizing radiation. PC3 cells were transiently transfected with either Luciferase (siLUC) or MEK5 (siMEK5-10) siRNA and serum starved for $48 \mathrm{~h}$. Cells were irradiated with $4 \mathrm{~Gy}$ and lysed at the indicated time points. Levels of total MEK5 and a-tubulin are shown. $\mathbf{c}$ PC3 stably expressing a scrambled (shControI) or MEK5 (clone\#12) shRNA were irradiated with 3 Gy $\gamma$-rays and immunoblotted subsequently with phospho-ERK5, total ERK5, MEK5, and a-tubulin antibodies. d DU145 clonogenic survival assay. DU145 cells were either left untransfected (DU) or transiently transfected with luciferase siRNA (DL) or four different siRNAs against MEK5 (D76, D78, D10, D20). Two days later, cells were irradiated with increasing doses of $\gamma$-radiation and plated for clonogenic assay. e PC3 cells were transfected with luciferase siRNA (PL) as control or MEK5 siRNAs (P76, P78) and clonogenic assay was carried out as in d. f Cell proliferation assay. DU145 and PC3 cells were transiently transfected with control Luciferase (LUC) or MEK5 (D78 or P78) siRNA. Three days later, cells were irradiated with $4 \mathrm{~Gy} \gamma$-rays and incubated for 6 days. Cells were trypsinized and counted with a hemocytometer. g DU145 and PC3 cells were stably expressing either scrambled (shControl) or MEK5 (shMEK5) shRNA were exposed to 4 Gy (DU145) or 3 Gy (PC3), or were sham irradiated. Data for $d, e$, and $f$ represent the mean \pm S.D $(n=3)$. P-values were calculated by Student's t-test. UI: unirradiated. 

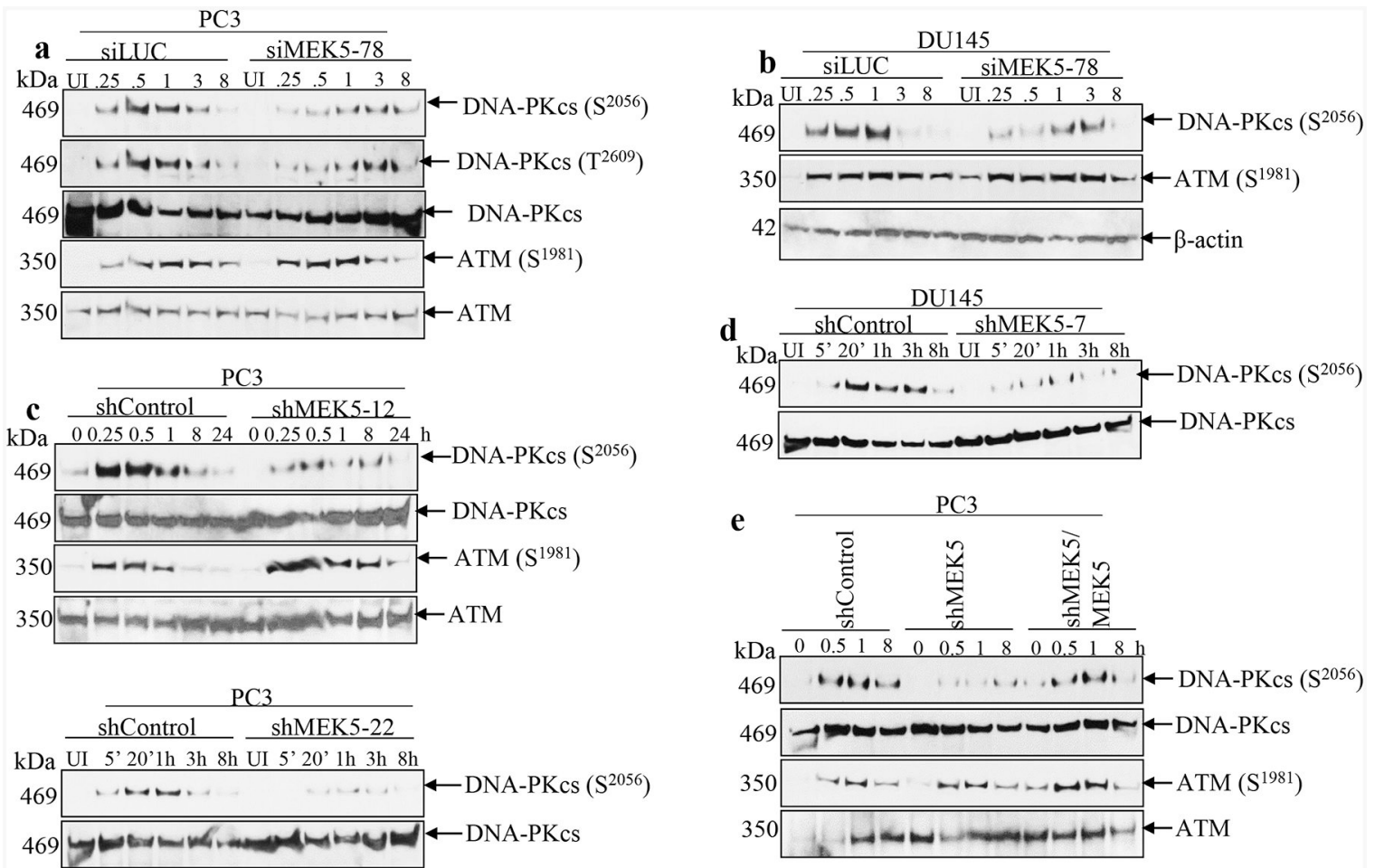

Fig. 2.

MEK5 knockdown impairs DNA-PKcs phosphorylation in response to ionizing radiation. PC3 (a) or DU145 (b) cells were transiently transfected with Luciferase siRNA (siLUC) or siRNAs against MEK5 (\#78). Four days later, cells were irradiated with $3 \mathrm{~Gy} \gamma$-radiation, lysates were prepared at the indicated times and immunoblotted with the indicated antibodies. c PC3 cells stably expressing a control (shControl) or MEK5 (clone\#12, upper, clone\#22, lower) shRNA were exposed to 3 Gy of $\gamma$-rays and cells were lysed at the indicated times. Lysates were immunoblotted sequentially with the indicated antibodies. d DU145 cells stable expressing a scrambled (shControl) or MEK5 (clone\#7) shRNA were exposed to $3 \mathrm{~Gy}$ of $\boldsymbol{\gamma}$-rays and cells were lysed at different times and immunoblotted sequentially with anti-phospho-DNA-PKcs (S2056) and anti-total DNA-PKcs antibodies. e Ectopic expression of MEK5 restores activation of DNA-PKcs. PC3 cells stably expressing shControl, shMEK5 (clone\#12), or shMEK5 transiently expressing MEK5-pcDNA3 vector were exposed to $3 \mathrm{~Gy}$ of $\gamma$-rays and lysed at the indicated times. Lysates were immunoblotted sequentially with phospho-DNA-PKcs (Ser2056), total DNA-PKcs, phospho-ATM (Ser1981) and total ATM antibodies. UI: unirradiated. 
a

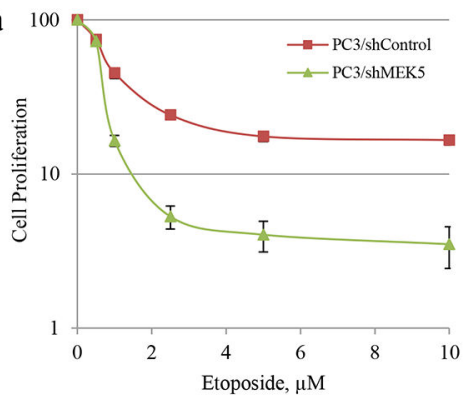

d

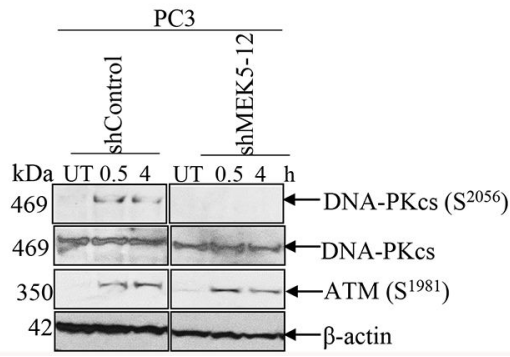

b

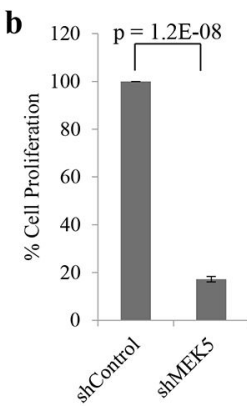

PC3

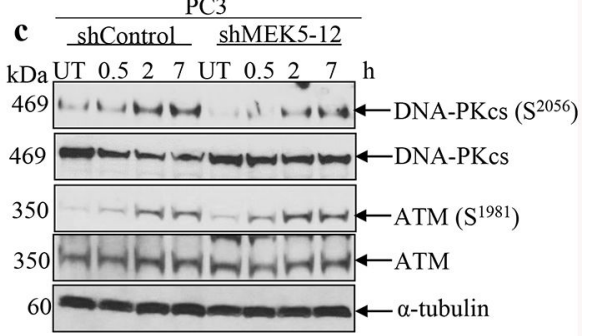

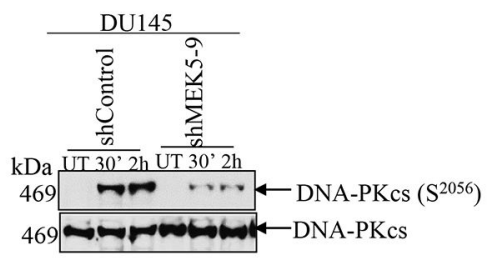

Fig. 3.

MEK5 knockdown impairs DNA-PKcs phosphorylation in response to etoposide and phleomycin. a dose response curves of control and MEK5 shRNA in PC 3 cells exposed to increasing concentrations of etoposide. Cell numbers were recorded 6 days post-treatment. b PC3 cells were exposed to $10 \mu \mathrm{M}$ etoposide for $16 \mathrm{~h}$, drug was removed, and cells were incubated for 6 days. Subsequently, cells were fixed, stained with crystal violet, quantified and expressed as percentage of the shControl-treated cells. Mean \pm S.D. $(\mathrm{n}=3)$. P-value were calculated by Student's t-test. $\mathbf{c}$ PC3 cells stably expressing a scrambled (shControl) or MEK5 (clone \#12) shRNA were treated with $10 \mu \mathrm{M}$ etoposide, cells were lysed at the indicated times and immunoblotted sequentially with the indicated antibodies. $\mathbf{d}$ PC 3 cells (left) stably expressing shControl or shMEK5 (clone \#12) and DU145 cells (right) stably expressing shControl or shMEK5 (clone \#9) were treated with $60 \mu \mathrm{g} / \mathrm{ml}$ phleomycin for $2 \mathrm{~h}$, drug was removed and cells were incubated for the indicated times. Lysates were immunoblotted with the indicated antibodies. UT: untreated. 
a

PC3/shControl

PC3/shMEK5

DAPI

UI

$0.5 \mathrm{~h}$

$2 \mathrm{~h}$

$8 \mathrm{~h}$

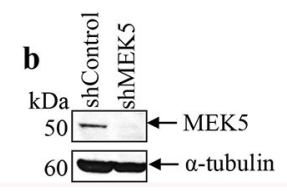

Fig. 4. $\gamma \mathrm{H} 2 \mathrm{AX}$
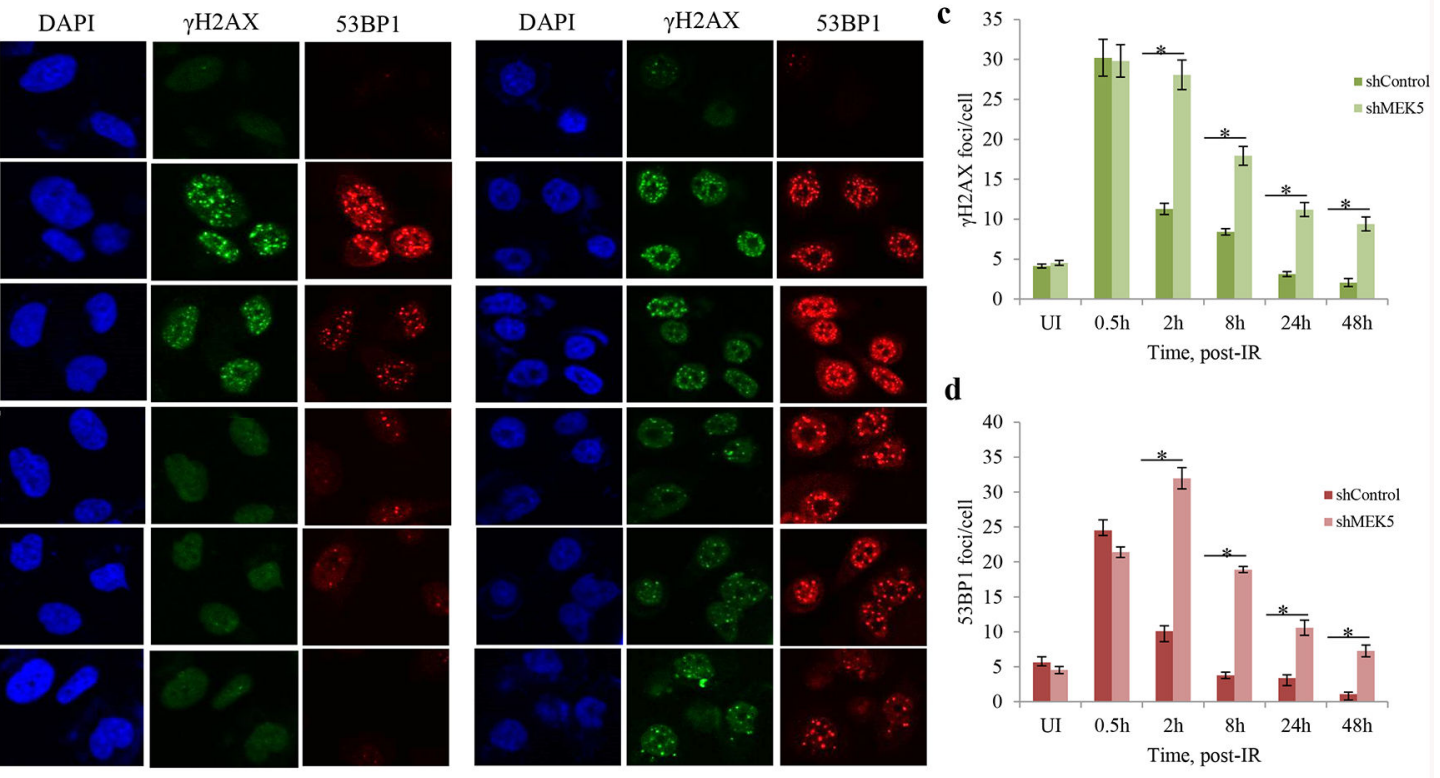

d

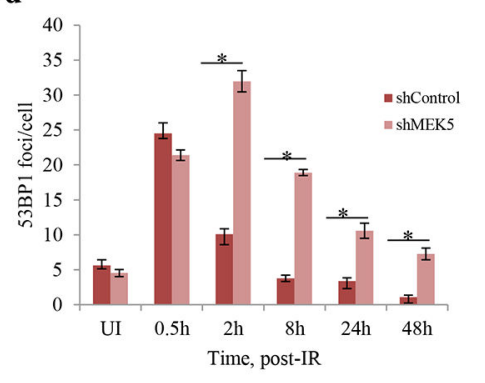

MEK5 knockdown delays resolution of irradiation-induced DSBs. PC3 cells stably expressing shControl or shMEK5 were exposed to 3 Gy $\gamma$-rays, fixed and stained for $\gamma \mathrm{H} 2 \mathrm{AX}$, 53BP1, and 4', 6-diamidino-2-phenylindole (DAPI; DNA). a Representative images and $\mathbf{b}$ western blot analysis of MEK5 protein levels in shControl and shMEK5 (clone \#12) cells. c, $\mathbf{d}$ quantitation of number of $\gamma \mathrm{H} 2 \mathrm{AX}$ (c) and 53BP1 (d) foci per cell over time after irradiation between cells expressing shControl and shMEK5. Shown mean \pm S.D. (n = 3). ${ }^{*} \mathrm{p}<0.001$, calculated by Student's t-test. UI: unirradiated. 
$\mathbf{a}$ PC3/shControl
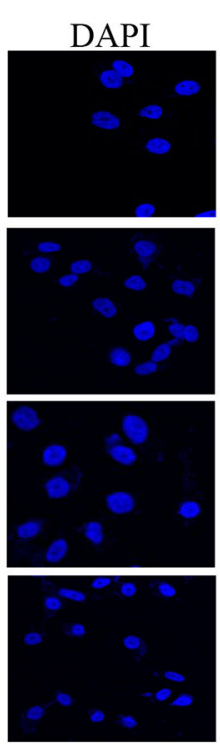

$\gamma \mathrm{H} 2 \mathrm{AX}$
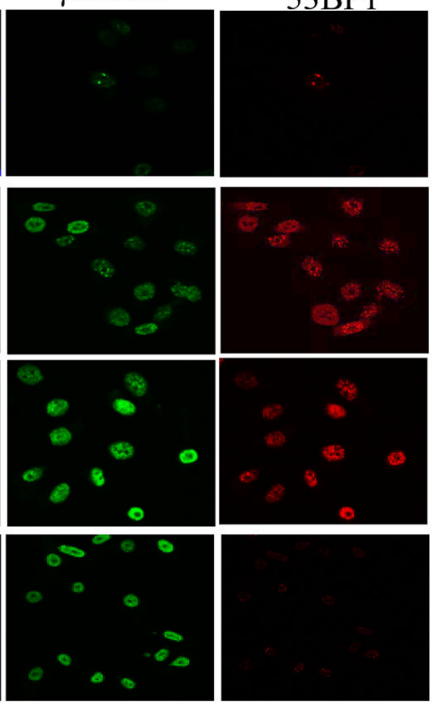
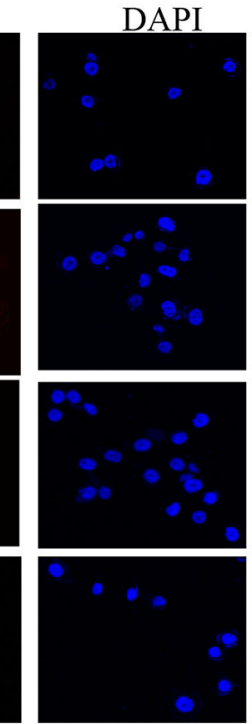

PC3/shMEK5
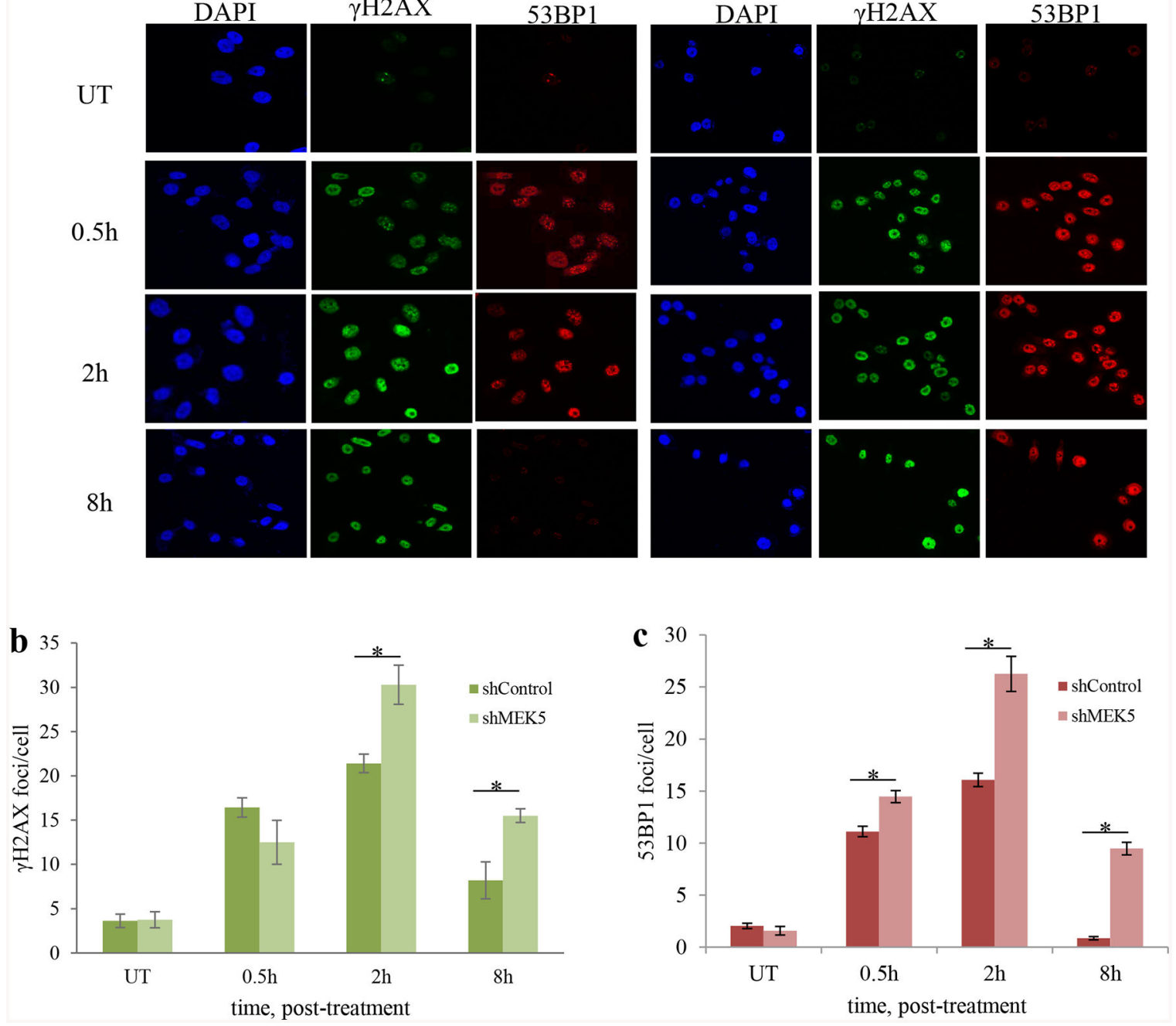

Fig. 5.

MEK5 knockdown delays resolution of etoposide-induced DSBs. PC3 cells stably expressing shControl or shMEK5 were treated with etoposide and, at the indicated times, they were fixed and stained for $\gamma \mathrm{H} 2 \mathrm{AX}, 53 \mathrm{BP} 1$, and 4', 6-diamidino-2-phenylindole (DAPI; DNA). a Representative images and $\mathbf{b}, \mathbf{c}$ quantitation of number of $\gamma \mathrm{H} 2 \mathrm{AX}$ (b) and 53BP1 (c) foci per cell over time after etoposide treatment between cells expressing shControl and shMEK5. Shown mean \pm S.D. $(\mathrm{n}=3)$. * $\mathrm{p}<0.001$, calculated by Student's t-test. UT: untreated. 


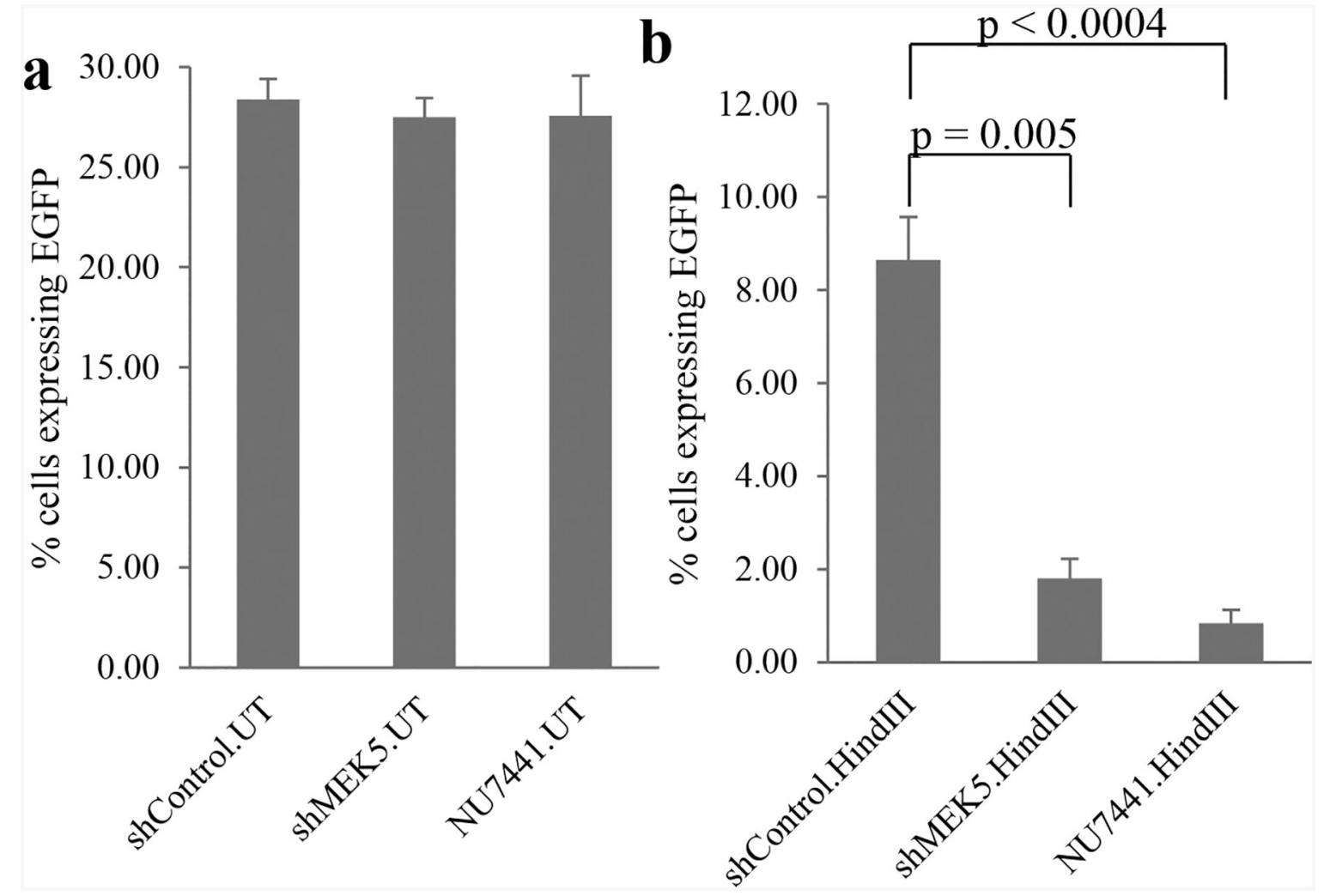

Fig. 6.

MEK5 depletion impairs non-homologous end joining. a intact or b HindIII-digested pEGFP-N1 vector was transiently transfected in PC3 cells expressing shControl or shMEK5. shControl cells were also treated or not with NU7441. Twenty-four hours post-transfection, cells were fixed, stained with DAPI, and EGFP-positive cells were quantitated by fluorescence as percent EGFP-positive cells/total (DAPI) number cells. Mean \pm S.D. $(n=3)$. P-value was calculated by Student's t-test. UT: uncut plasmid; HindIII: restriction enzymedigested plasmid. 


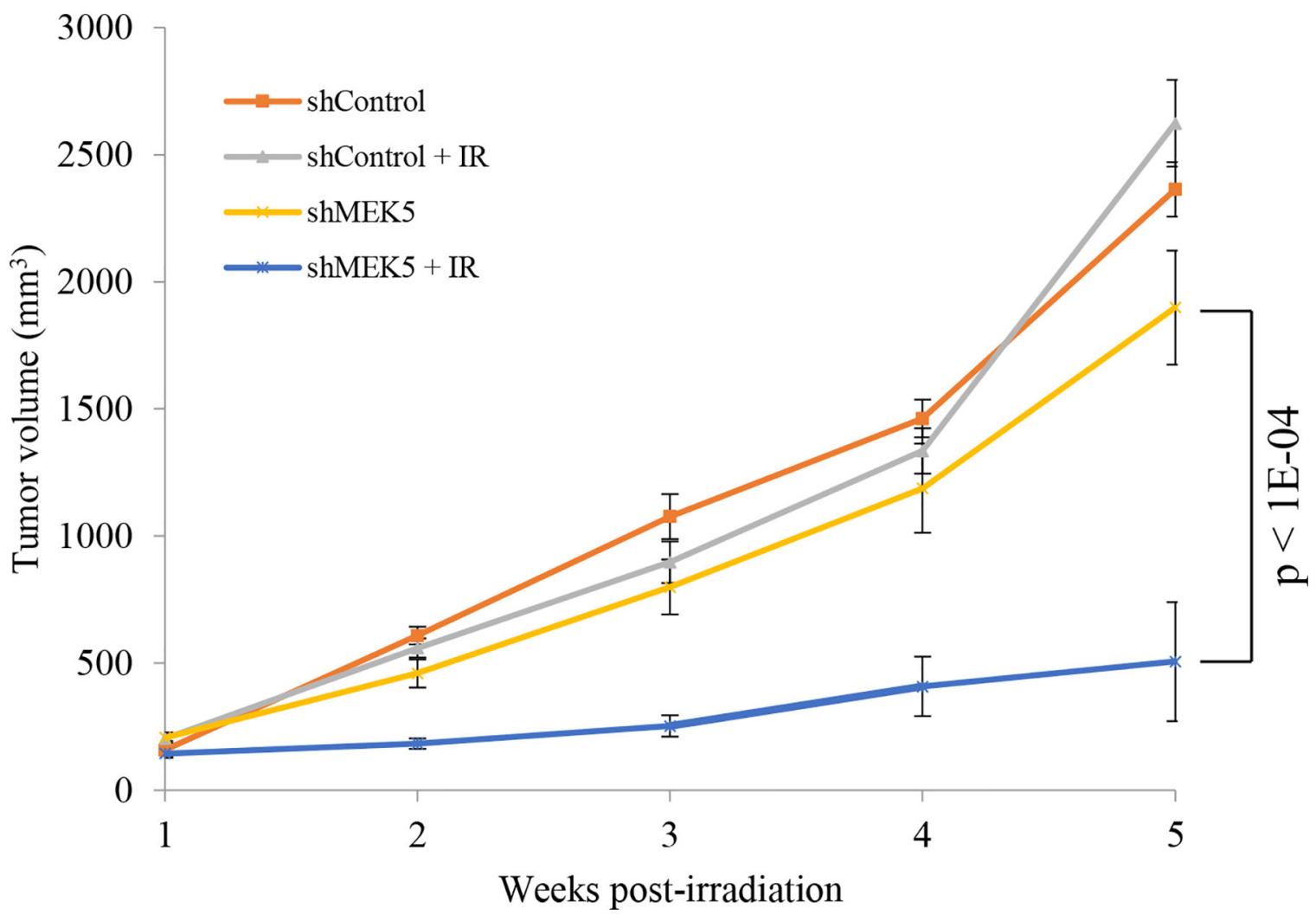

Fig. 7.

MEK5 ablation synergizes with radiotherapy to suppress PC3 tumor growth in vivo. PC3 cells stably expressing scrambled (control) or MEK5 (clone \#12) shRNA were injected subcutaneously into athymic male NU/J mice. When tumors reached $\sim 200 \mathrm{~mm}^{3}$, mice were irradiated with 4 Gy x-rays (IR), or they were sham irradiated. Tumor growth was measured using a caliper. Shown mean volume \pm S.E.M. $(n=8$ mice $/$ treatment $)$. 